\title{
Morphological-Image Analysis Based Numerical Modelling of Organoclay Filled Nanocomposites
}

\author{
Y. Dong a and D. Bhattacharyya, ${ }^{\text {b,* }}$ \\ ${ }^{a}$ Department of Mechanical Engineering, Curtin University of Technology \\ GPO Box U1987, Perth, WA 6845, Australia \\ ${ }^{\mathrm{b}}$ Centre for Advanced Composite Materials, Department of Mechanical Engineering \\ The University of Auckland, Private Bag 92019 \\ Auckland, New Zealand
}

\begin{abstract}
This paper introduces a novel numerical approach, object-oriented finite element (OOF) technique to incorporate the acquired nanocomposite morphological images into two-dimensional finite element modelling. The overall material behaviour can be reasonably well understood combining real data from microstructures with the fundamental material characteristics of constitutive phases. Morphological images, using both scanning electron microscope (SEM) and transmission electron microscope (TEM), are utilised to generate the geometric micro/nano structure. Numerical results predicting the tensile properties of polypropylene (PP)/organoclay nanocomposites are compared with experimental data and theoretical composite models very well, thus establishing the viability of our numerical approach in a nanocomposite system.
\end{abstract}

Key words: organoclay filled nanocomposites, object-oriented finite element (OOF) modelling, micro/nano structure, SEM and TEM, tensile properties

\footnotetext{
*Address correspondence to D. Bhattacharyya, Department of Mechanical Engineering, The University of Auckland, Private Bag 92019, Auckland, New Zealand.

Email: d.bhattacharyya@auckland.ac.nz.
} 


\section{INTRODUCTION}

Due to excellent property enhancement and the versatile applications in automotive and packaging industries, polymer/clay nanocomposites are intensively researched as the innovative replacement of the conventional composite materials [14]. Such nanocomposites can be ideally classified to be intercalated and/or exfoliated according to their different morphological structures. Nevertheless, in the real morphology, partially intercalated and exfoliated nanocomposites are normally formed, which creates a very complex heterogeneous material system. The irregular shapes and sizes of the dispersed clay platelets with the random orientation states are inevitably challenging to understand the relationship between the processing, the developed morphology and the resulting properties. Numerical modelling techniques such as molecular dynamic (MD) simulation and finite element method (FEM) have been found for decades to be more effective approaches compared to the analytical models. Since most nanocomposites contain the nanoscale fillers like carbon nanotubes, nanoclays and nanofibres, molecular dynamic simulation [5-6] have been employed to accurately predict the properties of nanocomposites with the tedious computational efforts to scale up the time and the integrated length. Alternatively, representative volume elements (RVE) have been implemented with either wellaligned [7-8] or Monte Carlo type randomly distributed [9-11] patterns, which might not represent the actual complex and highly heterogeneous nanocomposite structures. Consequently, effective modelling and prediction of the mechanical properties of nanocomposites are still at infancy for the design and development of such highperformance materials to be used by the composites manufacturers and engineers. 
In this study, a novel numerical approach Object-Oriented Finite Element (OOF) [12-13] analysis is utilised by mapping the real micro/nano morphological images of $\mathrm{PP} /$ organoclay nanocomposites with clay contents varying between $1 \mathrm{wt} \%$ and $10 \mathrm{wt} \%$. Such morphological images are captured by two different microscopic techniques: SEM and TEM analyses. The tensile moduli of nanocomposites are numerically predicted and subsequently compared with the tensile test data. Furthermore, the available composites models are used to compare the numerical approach developed in this study. Finally, the effect of particle distribution on the deformation behaviour is also evaluated through the tensile stress and elastic strain contours of such nanocomposites.

\section{EXPERIMENTAL}

\section{Materials and Fabrication Process}

NANOLIN DK2 organomodified montmorillonite (MMT) clay was purchased from Zhejiang FengHong Clay Chemicals Co., Ltd, China. Polypropylene copolymer Hi-rene M710 with $6 \mathrm{wt} \%$ ethylene content (density $0.9 \mathrm{~g} / \mathrm{cm}^{3}$ and melt flow index $0.6 \mathrm{~g} / 10 \mathrm{~min}$ at $230^{\circ} \mathrm{C}$ ) was obtained from Clariant New Zealand Ltd. Maleated polypropylene (MAPP) Exxelor PO 1020 (MA content: 0.5-1.0 wt\%, density 0.9 $\mathrm{g} / \mathrm{cm}^{3}$ and melt flow index $\sim 430 \mathrm{~g} / 10 \mathrm{~min}$ at $230^{\circ} \mathrm{C}$ ), supplied by ExxonMobil Chemical, Germany, was used as the compatibiliser.

$\mathrm{PP} /$ organoclays nanocomposites were prepared in pellet form using a co-rotating intermesh twin screw extruder (Brabender DSE 20) with a screw length-diameter ratio of $40: 1$ (diameter $\mathrm{D}=20 \mathrm{~mm}$ ) at $185-210^{\circ} \mathrm{C}$ and $200 \mathrm{rpm}$. Two-step masterbatch compounding was employed in this study. Premixed organoclays and MAPP powders (1:1 weight ratio) were melt compounded to make the masterbatch which were further let down into PP pellets to prepare nanocomposites with the clay contents of $1 \mathrm{wt} \%$, 
$3 \mathrm{wt} \%, 5 \mathrm{wt} \%$ and $10 \mathrm{wt} \%$ (denoted as NC1, NC3, NC5 and NC10, respectively). The dried nanocomposite pellets were then injection moulded using a BOY 50A injection moulder to make the tensile specimens at a temperature profile of $190-210{ }^{\circ} \mathrm{C}$ and injection pressure of 70-80 bars. Neat PP was also processed in the identical conditions for comparison.

\section{Morphological Image Analysis}

Morphological images were based on SEM and TEM analyses for the geometric information on nanocomposite structures. A Philips XL30S Field Emission Gun SEM machine was in operation at $5.0 \mathrm{kV}$. Prior to the platinum sputter coating, SEM surfaces were generated by cryofracturing tensile specimens along the longitudinal direction for further OOF modelling work.

Similarly, TEM ultra thin film samples (nominal thickness: 70nm) was also crysectioned in the longitudinal direction using a Hitachi S-4700 ultramicrotome at $80{ }^{\circ} \mathrm{C}$. The prepared samples were subjected to TEM analysis using a Philips CM12 TEM at an accelerating voltage of $120 \mathrm{kV}$.

The original SEM and TEM images were processed using Photoshop 7.0 software to adjust their contrast and the brightness for the best image quality. Subsequently, the region of interest for nanocomposite morphology was selected based on the microstructural features as well as the availability of the computational capacity in OOF modelling. Figure 1 shows the typical example of SEM and TEM images of $5 \mathrm{wt} \%$ filled nanocomposites with the respective representative regions of interest. A region of interest was taken in the size of approximately $6.15 \mu \mathrm{m} \times 4.10 \mu \mathrm{m}$ from the SEM image captured at $20000 \times$ magnification and $6.62 \mu \mathrm{m} \times 6.62 \mu \mathrm{m}$ from the TEM image at $15000 \times$ magnification. The scale bars were later erased in Photoshop to distinguish them from the clay particles. 


\section{Tensile Testing}

The tensile properties of the specimens were measured according to ASTM D638, using an Instron Universal Testing Machine 1185 with Bluehill 2 software. The chord tensile modulus (0.05 0.25\% strain) and tensile strength at yield were determined at the corresponding crosshead speed of $5 \mathrm{~mm} / \mathrm{min}$ and $50 \mathrm{~mm} / \mathrm{min}$. More than ten specimens were tested with the calculated mean values and standard deviations used in the final results.

\section{COMPOSITES THEREOTICAL MODELS}

\section{Halpin-Tsai Model}

Halpin-Tsai model [14] is most widely used in the fibre composites industry to predict the tensile moduli of unidirectional composites as the function of aspect ratio. This model can deal with a variety of reinforcement geometry including discontinuous filler reinforcement such as fibre-like or flake-like fillers. The Young's modulus of a composite material in Halpin-Tsai model is proposed as

$$
\begin{gathered}
\frac{E_{c}}{E_{m}}=\frac{1+\zeta \eta \phi_{f}}{1-\eta \phi_{f}} \\
\eta=\frac{\frac{E_{f}}{E_{m}}-1}{\frac{E_{f}}{E_{m}}+\zeta}
\end{gathered}
$$

where $E_{c}, E_{f}, E_{m}$ are Young's moduli of composite material, filler and polymer matrix, respectively. $\phi_{f}$ is the filler volume fraction and $\zeta$ is a shape parameter dependent on filler geometry and loading direction. In particular, $\zeta=2(l / d)$ for fibres or 
$2(l / t)$ for disk-like platelets where $l, d, t$ are the length, diameter and thickness of the dispersed filler.

In fact, 2-D disk-like unidirectional clay platelets can make less contribution to modulus compared to 1-D fibre-like filler. Therefore, a modulus reduction factor (MRF) which is set to 0.66 [15] is introduced to modify Halpin-Tsai model as

$$
\frac{E}{E_{m}}=\frac{1+\zeta(M R F) \eta \phi_{f}}{1-\eta \phi_{f}}
$$

\section{Hui-Shia Model}

Hui-Shia model [16-17] is developed to predict the tensile moduli of composites including unidirectional aligned platelets with the simple assumption of perfect interfacial bonding between the polymer matrix and platelets, which can be expressed as

$$
\begin{gathered}
\frac{E_{c}}{E_{m}}=\frac{1}{1-\frac{\phi_{f}}{4}\left[\frac{1}{\xi}+\frac{3}{\xi+\Lambda}\right]} \\
\xi=\phi_{f}+\frac{E_{m}}{E_{f}-E_{m}}+3\left(1-\phi_{f}\right)\left[\frac{(1-g) \alpha^{2}-\frac{g}{2}}{\alpha^{2}-1}\right] \\
g=\frac{\pi}{2} \alpha \\
\Lambda=\left(1-\phi_{f}\right)\left[\frac{3\left(\alpha^{2}+0.25\right) g-2 \alpha^{2}}{\alpha^{2}-1}\right]
\end{gathered}
$$

where $\alpha$ is the inverse aspect ratio of the dispersed filler and $\alpha=t / l$ for disk-like platelets $(\alpha \leq 0.1)$

\section{Voigt Upper Bound and Reuss Lower Bound}


When $\zeta \rightarrow \infty$, the Halpin-Tsai model equations reach the upper bound, which is normally called Voigt rule of mixtures (ROM) [18] where fibre and matrix have the same uniform strain (i.e. isostrain approach):

$$
E_{c}=\phi_{f} E_{f}+\left(1-\phi_{f}\right) E_{m}
$$

Conversely, when $\zeta \rightarrow 0$, the Halpin-Tsai model equations reach the lower bound under equal stress (i.e. isostress approach), so-called Reuss inverse rule of mixtures (IROM) [19]:

$$
\frac{1}{E_{c}}=\frac{\phi_{f}}{E_{f}}+\frac{\left(1-\phi_{f}\right)}{E_{m}}
$$

Both Voigt and Reuss models provide initial estimates of the upper and lower bounds of the elasticity of multiphase composites with the only consideration of the filler volume fraction but irrespective of filler shape/geometry, orientation and spatial arrangement.

\section{Elastic Properties of Effective Clay Particles}

Since the formation of PP/clay nanocomposites normally contains the prevalent good clay intercalation instead of complete exfoliation in the dispersion state, the "effective particles" [10] for intercalated clay platelets can be simplified as the basic discrete elements in OOF modelling with the stacks of layer structures illustrated in Figs. 2(a) and (b). Furthermore, such effective particles are approximated to be ideally isotropic homogenised particles characterised by the simple elastic modulus $\mathrm{E}_{\mathrm{p}}$ and Poisson's ratio $v_{\mathrm{p}}$. Hence, their elastic modulus $\mathrm{E}_{\mathrm{p}}$ is estimated by the following rule of mixtures [20-22]:

$$
E_{p}=\phi_{M M T} E_{M M T}+\phi_{\text {gallery }} E_{\text {gallery }} \approx \phi_{M M T} E_{M M T} \approx\left(\frac{d_{M M T}}{d_{001}}\right) E_{M M T}
$$


provided that

$$
E_{\text {gallery }}<<E_{M M T}
$$

where $\phi_{M M T}$ and $\phi_{\text {galley }}$ are the volume fractions of silicate layers in the stack and gallery space (i. e. interlayer area), respectively. $\mathrm{E}_{\text {gallery }}$ is the modulus of the gallery material which is expected to be much less than the elastic modulus of MMT ( $\mathrm{E}_{\mathrm{MMT}}$ ) $[21,22] . \phi_{M M T}$ can be well approximated from the ratio of the interlayer spacing $\mathrm{d}_{\mathrm{MMT}}$ of pure $\operatorname{MMT}\left(\mathrm{d}_{\mathrm{MMT}} \approx 1 \mathrm{~nm}\right)$ and the interlayer spacing $\mathrm{d}_{001}$ of intercalated nanocomposites obtained from XRD scans. In the special case of single clay platelet in a stack, the elastic modulus of exfoliated clay particles is much higher, which is assumed to be equal to that of muscovite $\left(\mathrm{E}_{\mathrm{p}}=178 \mathrm{GPa}\right)$ [22].

The Poisson's ratio of the intercalated clay platelets, also estimated in a similar way $[10,21]$, can be calculated as

$$
v_{p}=\phi_{M M T} v_{M M T}+\phi_{\text {gallery }} v_{\text {gallery }}
$$

where Poisson's ratios $v_{\mathrm{MMT}}=0.20$ [22] and $v_{\text {gallery }}=0.35-0.50$ [21]. $v_{\mathrm{p}}=0.26$ is assigned due to the insensitivity of Poisson's ratio of the intercalated clay particles within the range $0.26-0.32$ [21].

\section{OOF Modelling}

A two-dimensional object-oriented finite element code OOF2 version 2.0.3 [12], developed by the National Institute of Standards and Technology (NIST), USA was installed in a Fedora Red Hat Core 4 Linux system. All finite element analyses were conducted on a Dell INSPIRON 8600 laptop with the dual boot system of Windows $\mathrm{XP}$ and Linux using 1.6 GHz processors and $2 \mathrm{~GB}$ of RAM.

OOF2 can correlate the heterogeneous material structure based on the real images with the bulk physical properties. Furthermore, OOF2 normally deals with complex small scaled and disordered system and includes details of microstructures such as 
particle size, shape and real orientation [13]. In general, OOF modelling procedure, shown in Figure 3, consists of six major steps: (1) capture the real image; (2) assemble the material properties for each constituents; (3) assign the material properties to the microstructure represented by groups of pixels; (4) generate the skeleton, only the geometry of FE mesh; (5) create FE mesh with boundary conditions and mathematical equations; (6) solve the models.

In this work, the computational tool OOF2 was used to predict the tensile moduli of PP/clay nanocomposites at various clay contents from $1 \mathrm{wt} \%$ to $10 \mathrm{wt} \%$. Since nanocomposites stretched at small strains less than $1 \%$ are still subject to elastic deformations, both clay particles and PP matrix are assumed to be linear elastic materials with perfect interfacial bonding between the two constituents. The material properties of the constituents used for this study are listed in Table 1. Typical OOF models of $5 \mathrm{wt} \%$ filled nanocomposites based on respective SEM and TEM morphological images are demonstrated in Figure 4. In terms of boundary conditions, as depicted in Figures 4(b) and (d), both $X$ and $Y$ displacements $U_{x}, U_{y}$ on the left boundary are set to zero (i.e. fully constrained) and $U_{x}$ on the right boundary is equivalent to $0.05 \%$ and $0.25 \%$ tensile strain, respectively. The tensile modulus is calculated from the tensile stress resulting from the sum of forces applied on the right boundary. Unit thickness and plane stress conditions are assumed throughout this study of OOF modelling.

\section{RESULTS AND DISCUSSION}

\section{Tensile Modulus}

OOF modelling results based on SEM and TEM morphological images are demonstrated along with the experimental data and the theoretical composite models, Figure 5. Both modelling results and experimental data lie within the Voigt upper 
bound and Reuss lower bound, the general limits for the elasticity of the multi-phase composites. Modelling results obtained from both SEM and TEM images have fairly good agreements with the experimental data despite the slight overestimation of tensile moduli, particularly for $1 \mathrm{wt} \%$ and $10 \mathrm{wt} \%$ filled nanocomposites. The possible reason might be attributed to the fact that this study ignored MAPP as the compatibiliser and the interphases between clay particles and PP matrix, both of which could lead to the different mechanical properties. In addition, very low contrast and poor phase distinction, more obvious in TEM images, are observed between clay particles and PP matrix. Hence, artefacts in image segmentation could also result in the inaccuracy of meshing and assignment of material properties based on the size and distribution of selected pixels. On the other hand, the microstructural region of interest in OOF modelling becomes more subjective for the clay contents of $1 \mathrm{wt} \%$ and $10 \mathrm{wt} \%$, due to the non-uniform clay dispersion by initial pulse feeding and clay agglomeration, respectively $[23,24]$.

OOF modelling results are also compared with theoretical composite models at two fixed aspect ratios $(\mathrm{L} / \mathrm{t}=10$ and $\mathrm{L} / \mathrm{t}=100)$, the thresholds of intercalated and exfoliated structures [25], respectively. It is suggested that a higher level of intercalation is more prevalent due to the much closer relationship of experimental and numerical results with the theoretical predictions at $\mathrm{L} / \mathrm{t}=10$. Furthermore, HuiShia model with $\mathrm{L} / \mathrm{t}=10$ gives the best agreement with the experimental data and OOF modelling (SEM) results, in comparison to original and modified Halpin-Tsai models. This happens most likely due to the specific platelet geometry for fillers in Hui-Shia model. As expected, modified Halpin-Tsai model agrees slightly better than HalpinTsai model, fitting OOF modelling (TEM) results very well. Therefore, introducing an 
MRF of 0.66 [15] due to 2-D disk-like platelet geometry could be effective for the tensile modulus prediction of PP/clay nanocomposites.

\section{Effect of Particle Distribution}

In order to understand the deformation mechanism of PP/clay nanocomposites, stress contours $\left(\sigma_{\mathrm{xx}}\right)$ under a uniaxial applied strain of $0.25 \%$ in OOF modelling (SEM) work are demonstrated in Figure 6, which contain different particle distributions resulting from varied clay contents between $1 \mathrm{wt} \%$ and $10 \mathrm{wt} \%$. More evidently, higher stress has been observed within the clay particles or in PP matrix immediately adjacent to the particles, which reveals the classical shear lag mechanism of the load transfer from the matrix to the particles. Furthermore, less variation of the stress distribution takes place in $3 \mathrm{wt} \%$ and $5 \mathrm{wt} \%$ filled nanocomposites due to more uniform clay dispersion, Figures 6 (b) and (c). As expected, the stress concentrations appear at the sharp corners of clay particles along the axial loading direction. In addition, concentration of stress can also be seen in the clustered regions where the clay particles are close to each other. Typical region A in Figure 6(d) shows a locally intensified maximum stress of over $0.29 \mathrm{GPa}$ for the matrix between two large clay clusters. As a result, the matrix in the clustered regions tends to yield at much lower levels of the macroscopic applied stress, which can inevitably cause the onset of clay particle cracking, initiating the damage of nanocomposites [26,27].

The elastic strain contours are also shown in Figure 7. Since the clay particles as platelet fillers are far more rigid than the PP matrix, the elastic strains become much lower inside the clay particles resulting in the most constraints of the matrix by the surrounding particles [27]. Similar to the stress contours, higher levels of elastic strain are detected around the sharp edges of the clay particles again parallel to the loading direction. The distribution of elastic strain in the homogeneous microstructures of $3 \%$ 
and $5 \mathrm{wt} \%$ filled nanocomposites is much more uniform than that of the clustered microstructure of $10 \mathrm{wt} \%$ filled nanocomposites. This finding, in view of the deformation mechanism, could explain the importance of clay dispersion in PP matrix as well as the adverse effects of the clay clusters in nanocomposites.

\section{CONCLUSION}

Object-oriented finite element analysis (OOF) has been successfully implemented to predict the tensile moduli of PP/clay nanocomposites and evaluate the particle distribution effect on the deformation mechanism under the linear elastic condition. OOF modelling results and experimental data show the predominant intercalated structures in the best agreement with Hui-Shia model $(\mathrm{L} / \mathrm{t}=10)$. Both SEM and TEM morphological image approaches have been found effective in the tensile modulus prediction in spite of the relative overestimation in some cases while using TEM images due to the artefacts and phase distinction problem. The study of particle distribution in the microstructures establishes the importance of uniform clay particle dispersion, without which clay clusters could lead to the localised stress concentrations, thus making the nanocomposites more prone to failure.

\section{ACKNOWLEDGEMENTS}

The authors would like to acknowledge Tertiary Education Commission (TEC) with Bright Future Top Achiever Doctoral Scholarship to Y. Dong and Foundation for Research Science and Technology (FRST), New Zealand for the research support. Technical assistance in OOF model development by Drs. Stephen Langer and SeungIll Haan from the National Institute of Standards and Technology (NIST), USA is also appreciated. 


\section{REFERENCES}

[1] Giannelis, E. P., "Polymer Layered Silicate Nanocomposites," Adv. Mater. 8, 29$35(1996)$.

[2] Varia, R. A., Price, G., Ruth, P.N., Nguyen, H.T., and Lichtenhan, J., "Polymer/Layered Silicate Nanocomposites as High Performance Ablative Materials,” Appl. Clay Sci.15, 67-92 (1999).

[3] Messersmith, P. B., and Giannelis, E. P., "Synthesis and Barrier Properties of Poly(E-caprolactone)-Layered Silicate Nanocomposites," J. Polym. Sci., Part A 33, 1047-1057 (1995)

[4] Kojima, Y., Usuki, A., Okada, A., Kurauchi, T., and Kamigaito, O., "Mechanical Properties of Nylon 6-Clay Hybrid,” J. Mater. Res. 8, 1179-1184 (1993).

[5] Buryachenko, V. A., Roy, A., Lafdi, K., Anderson, K. L., and Chellapilla, S., "Multi-Scale Mechanics of Nanocomposites including Interface: Experimental and Numerical Investigation,” Compos. Sci. Technol. 65, 2435-2465 (2005).

[6] Katti, K. S., Sikdar, D., Katti D. R., Ghosh, P., and Verma, D., "Molecular Interactions in Intercalated Oganically Modified Clay and Clay-Polycaprolactam Nanocomposites: Experiments and Modeling," Polymer 47, 403-414 (2006).

[7] Zhu, L. J., and Narh, K. A., "Numerical Simulation of the Tensile Modulus of Nanoclay-Filled Polymer Composites," J. Polym. Sci. 42, 2391- 2406 (2004).

[8] Fertig III, R. S., and Garnich, M. R., "Influence of Constituent Properties and Microstructural Parameters on the Tensile Modulus of a Polymer/Clay Nanocomposites,” Compos. Sci. Technol. 64, 2577-2588 (2004). 
[9] Sheng, N., Micro/Nanoscale Modelling of Anisotropic Mechanical Properties of Polymer/Layered-Silicate Nanocomposites, MSc thesis, Massachusetts Institute of Technology, Cambridge, 2002.

[10] Sheng, N., Boyce, M. C., Parks, D. M., Rutledge, G. C., Abes, J. I., and Cohen, R. E., "Multiscale micromechanical modelling of polymer nanocomposites and the effective clay particle," Polymer 45, 487-506 (2004).

[11] Liu, Y. J., and Chen, X. L., "Evaluations of the Effective Material Properties of Carbon Nanotube-Based Composites Using a Nanoscale Representative Volume Element," Mech. Mater. 35, 69-81 (2003).

[12] Langer, S. A., Reid, A. C. E., Haan, S. I., and Garcia, R. E., the OOF2 Manual: Revision 3.6 for OOF2 Version 2.0.3, National Institute of Standards and Technology (NIST), Gaithersburg, March 2007.

[on-line]: http://www.ctcms.nist.gov/ langer/oof2man/index.html

[13] Langer, S. A., Fuller Jr., E. R., and Carter, W.C., "OOF: an Image-Based FiniteElement Analysis of Material Microstructures,” Comput. Sci. Eng. 3, 15-23 (2001).

[14] Halpin, J. C., and Kardos, J. L., "The Halpin-Tsai Equations: a Review," Polym. Eng. Sci. 16, 344-352 (1976).

[15] Wu, Y. P., Jia, Q. X., Yu, D. S., and Zhang, L. Q., "Modeling Young's Modulus of Rubber-Clay Nanocomposites Using Composite Theories," Polym. Testing 23, 903-909 (2004).

[16] Hui, C. Y., and Shia, D., "Simple Formulae for the Effective Moduli of Unidirectional Aligned Composites," Polym. Eng. Sci. 38, 774-782 (1998).

[17] Shia, D. and Hui, C. Y., Burnside, S. D., and Giannelis, E. P., “An Interface Model for the Prediction of Young's Modulus of Layered Silicate-Elastomer Nanocomposites,” Polym. Compos. 19, 608-617 (1998). 
[18] Voigt, W., "Über Die Beziehung Zwischen den Beiden Elasticitätsconstanten Isotroper Körper,” Ann. Phys.38, 573-587 (1889).

[19] Reuss, A., "Berechnung der fliebgrenze von Mischkristalen auf Grund der Plastizitätsbedingung für Einkristalle," ZAMM 9, 49-58 (1929).

[20]Brune, D.A., and Nicerano, J., "Micromechanics of Nanocomposites: Comparison of Tensile and Compressive Elastic Moduli, and Prediction of Effects of Incomplete Exfoliation and Imperfect Alignment on Modulus”, Polymer 43, 369-387 (2002).

[21]Kim, D. H., Fasulo, P. D., Rodgers, W. R., and Paul, D. R., “ Structure and Properties of Polypropylene-Based Nanocomposites: Effect of PP-g-MA to Organoclay Ratio”, Polymer 48, 5308-5323 (2007).

[22]Fornes, T. D., and Paul, D. R., "Modeling Properties of Nylon 6/Clay Nanocomposites Using Composite Theories,” Polymer 44, 4993-5013 (2003).

[23]Dong, Y., Bhattacharyya, D., and Hunter, P. J., "Characterisation and ObjectOriented Finite Element Modelling of Polypropylene/Organoclay Nanocomposites," Key Eng. Mater. 334-335, 841-844 (2007).

[24] Dong, Y., Bhattacharyya, D., and Hunter, P. J., "Experimental Characterisation and Object-Oriented Finite Element Modelling of Polypropylene/Organoclay Nanocomposites," Compos. Sci. Technol., in press.

[25]Luo, J. J., and Daniel, I. M., "Characterization and Modelling of Mechanical Behaviour of Polymer/Clay Nanocomposites," Compos. Sci. and Technol. 63, 1607$1616(2003)$.

[26] Chawla, N., Patel B. V., Koopman, M., Chawla K. K., Saha R., Patterson, B. R., Fuller, E. R., and Langer, S. A., "Microstructure-Based Simulation of Thermomechanical Behaviour of Composite Materials by Object-Oriented Finite Element Analysis," Mater. Charact. 49, 395-407 (2003). 
[27]Ganesh, V. V., and Chawla N., "Effect of Particle Orientation Anisotropy on the tensile Behavior of Metal Matrix Composites: Experiments and Microstructure-Based Simulation”, Mater. Sci. Eng. A 391, 342-353 (2005).

\section{List of Figures:}

FIG. 1 Microstructural region of interest for $5 \mathrm{wt} \%$ filled nanocomposites: (a) SEM image at $20000 \times$ magnification and (b) TEM image at $15000 \times$ magnification.

FIG. 2. Illustrations of (a) 'effective particles' for intercalated clay platelets, (b) discrete stacks of layers structure and (c) ideally isotropic homogenised particles [10]. $\left(\mathrm{d}_{001}\right.$ : interlayer spacing, $\mathrm{d}_{\mathrm{MMT}}$ : interlayer spacing of pure MMT and $\mathrm{d}_{\mathrm{g}}$ : gallery thickness).

FIG. 3. Chart flow of OOF modelling procedure.

FIG. 4. Typical examples of OOF models based on SEM and TEM morphological images of $5 \mathrm{wt} \%$ filled nanocomposites: (a) and (c) are selected pixels containing clay particles (highlighted areas); (b) and (d) show FE meshes.

FIG. 5. Prediction of tensile moduli of PP/clay nanocomposites at various clay contents.

FIG. 6. Uniaxial stress $\left(\sigma_{\mathrm{xx}}\right)$ contours of $\mathrm{PP} /$ clay nanocomposites with varied clay contents (Ux $=0.25 \%$ strain): (a) $1 \mathrm{wt} \%$, (b) $3 \mathrm{wt} \%$, (c) $5 \mathrm{wt} \%$ and (d) $10 \mathrm{wt} \%$.

FIG. 7. Elastic tensile strain $\left(\varepsilon_{\mathrm{xx}}\right)$ contours of $\mathrm{PP} /$ clay nanocomposites with varied clay contents (Ux=0.25\% strain): (a) $1 \mathrm{wt} \%$, (b) $3 \mathrm{wt} \%$, (c) $5 \mathrm{wt} \%$ and (d) $10 \mathrm{wt} \%$. 


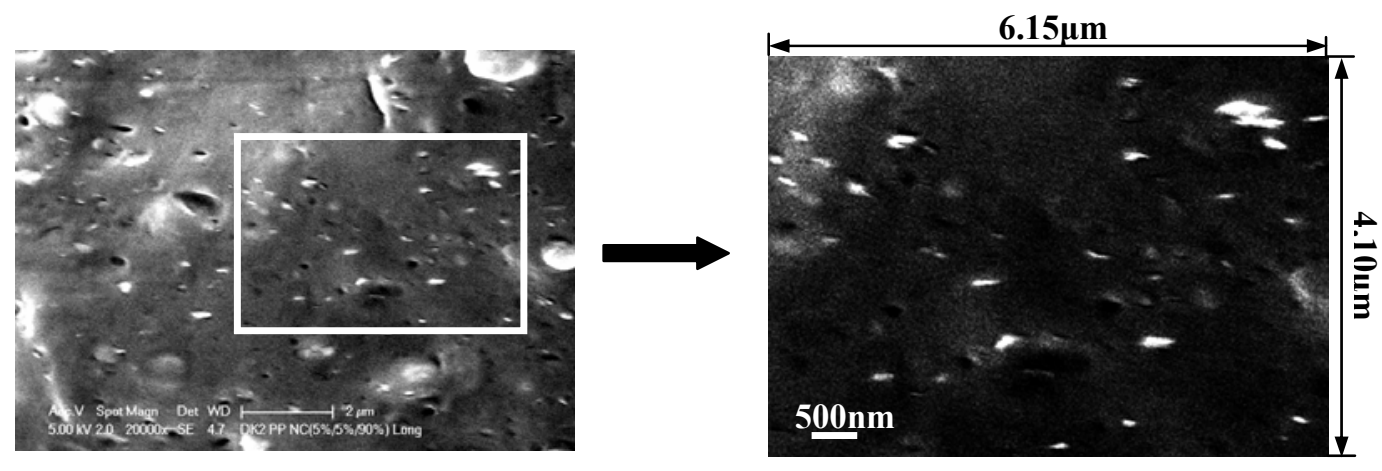

(a)

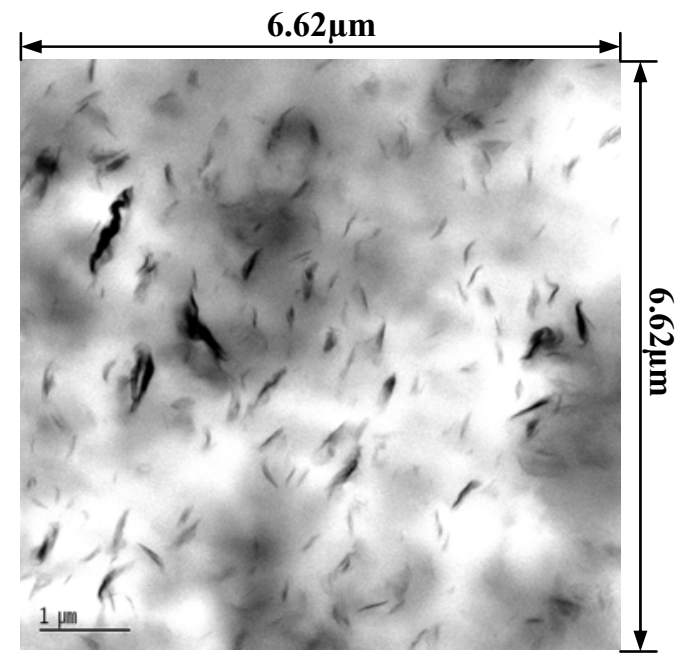

(b)

FIG. 1. 


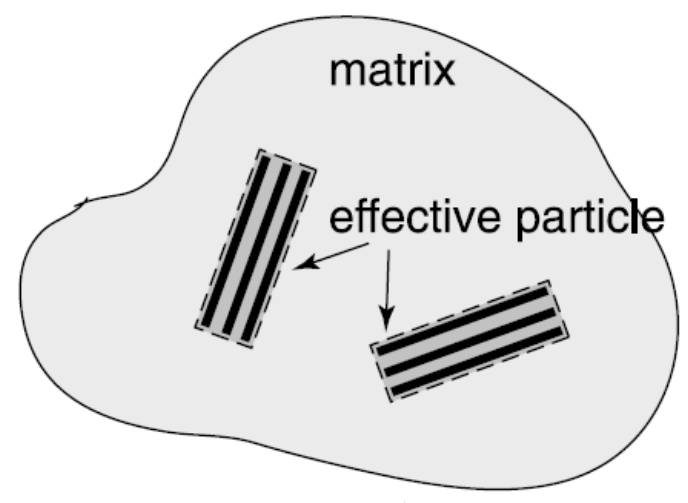

(a)

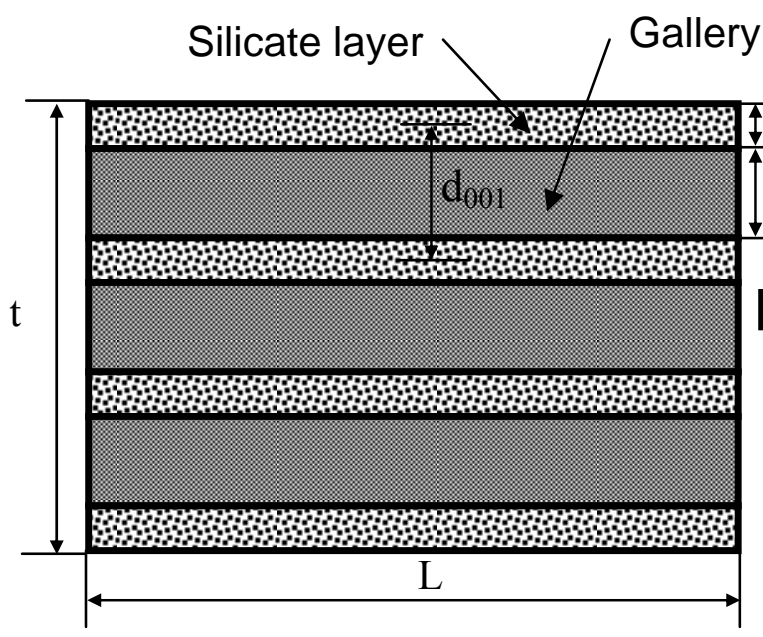

(b)

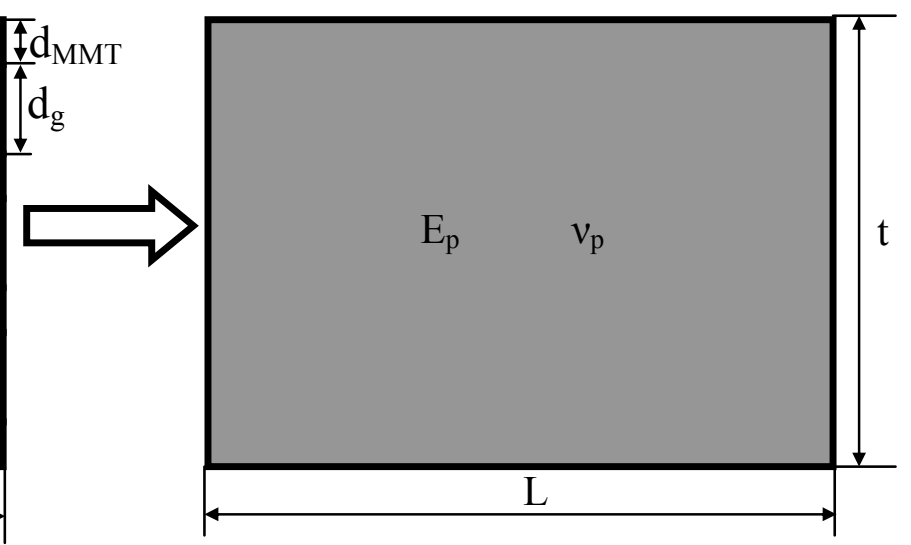

(c)

FIG. 2. 


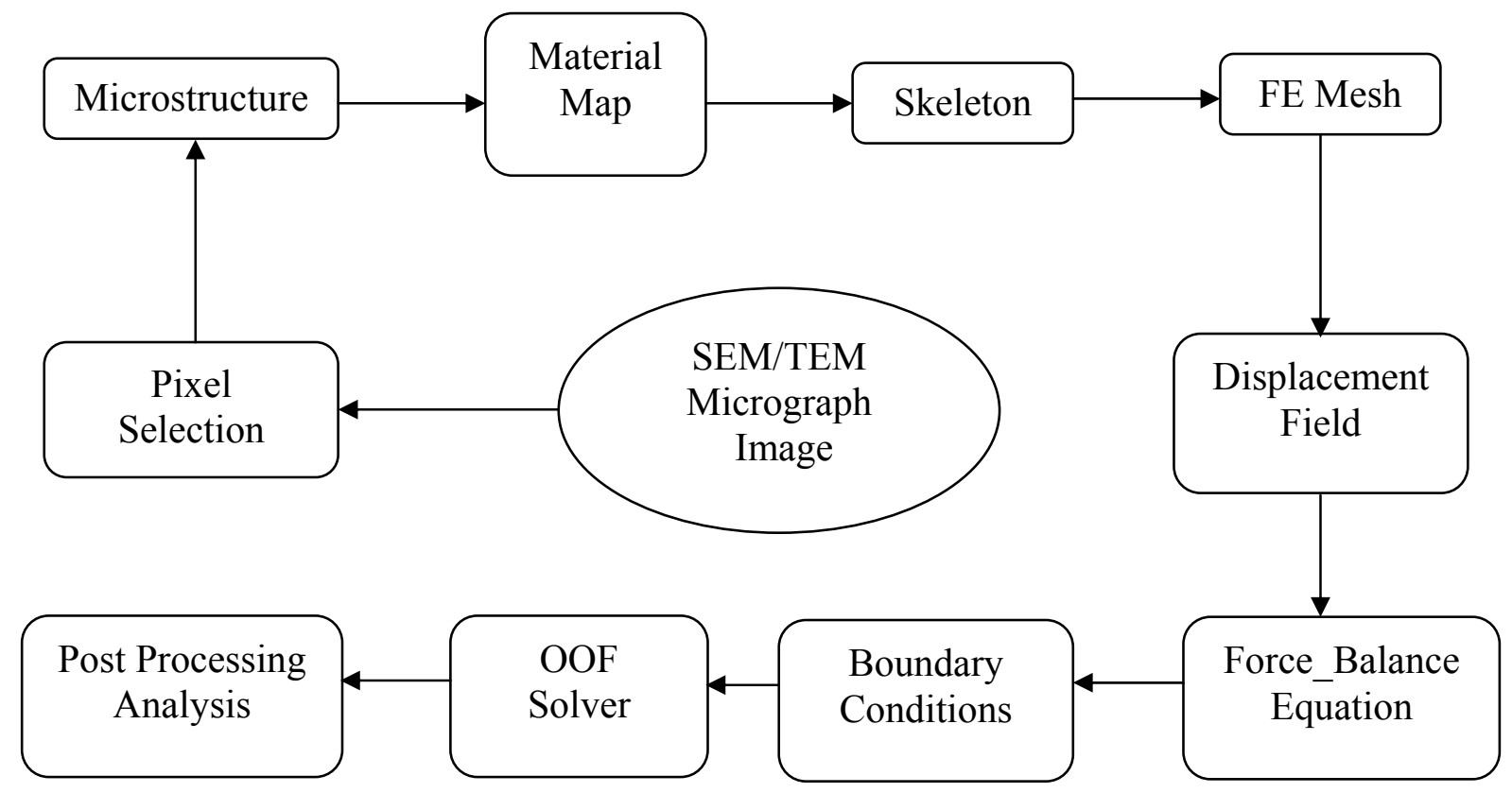

FIG. 3. 

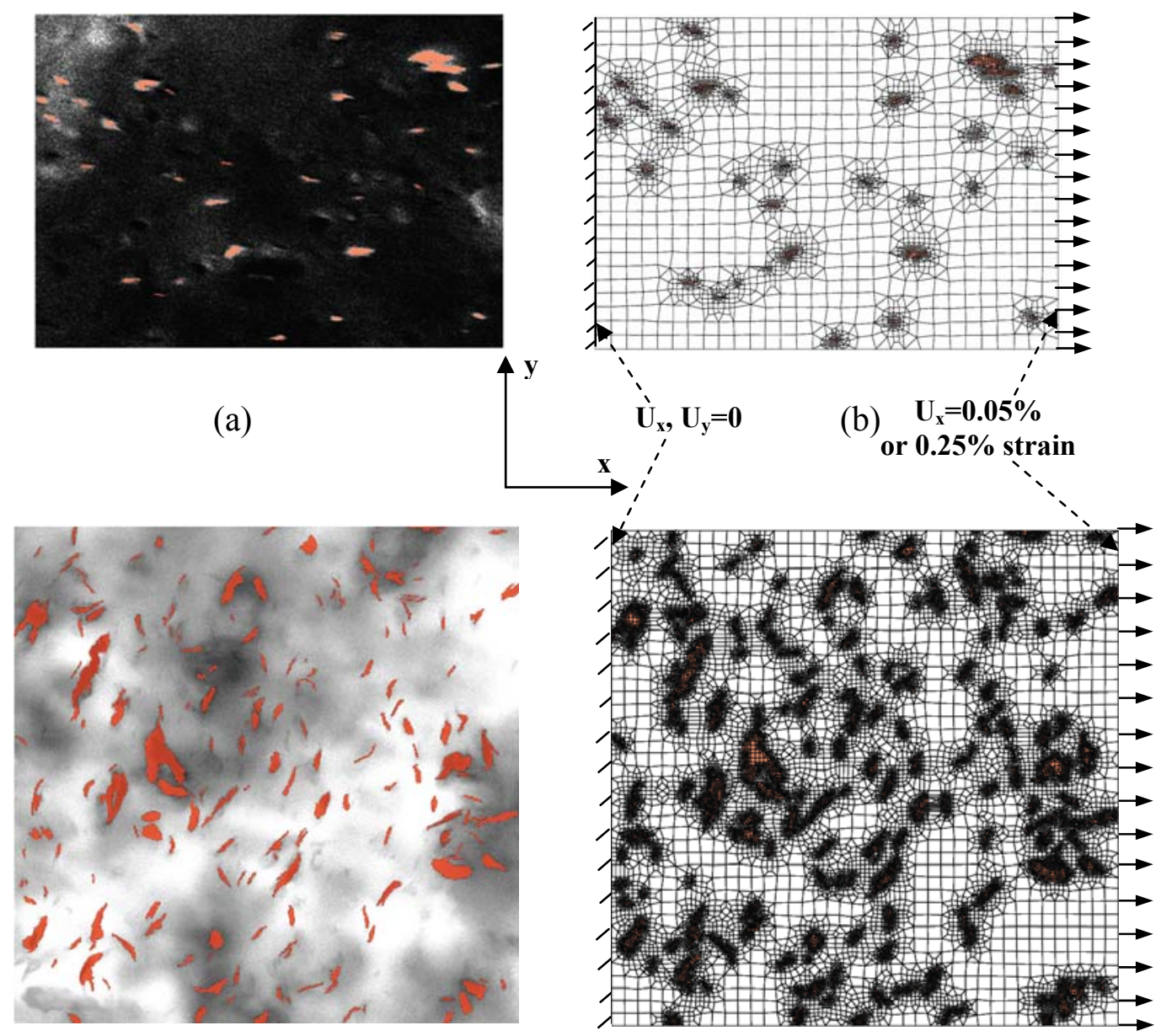

(c)

(d)

FIG. 4. 


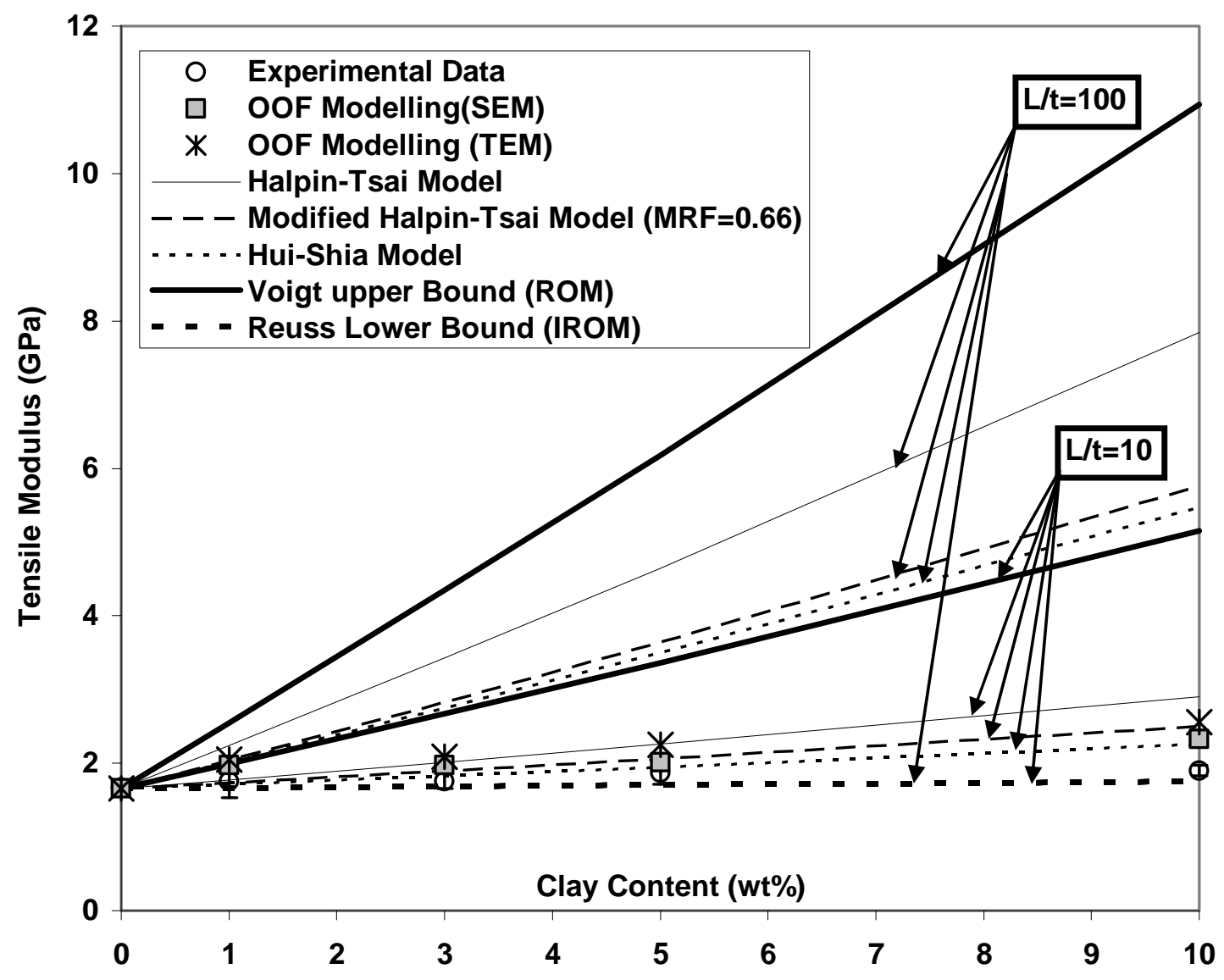

FIG. 5. 


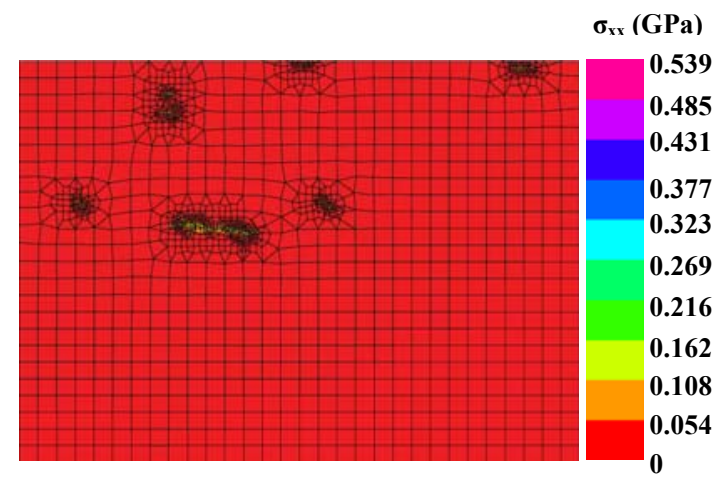

(a)

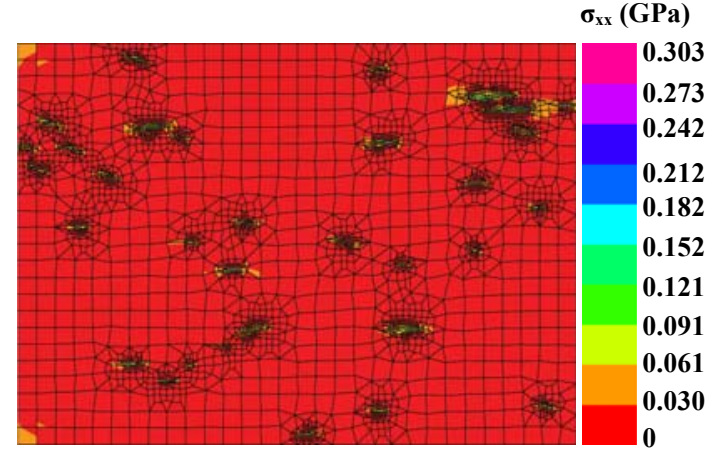

(c)

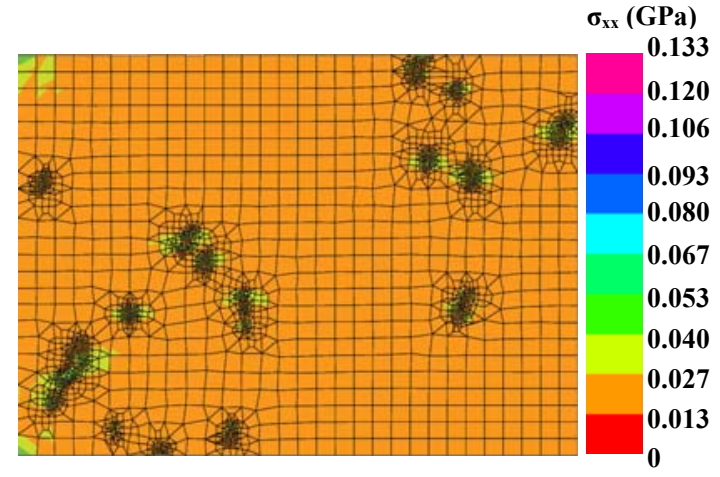

(b)

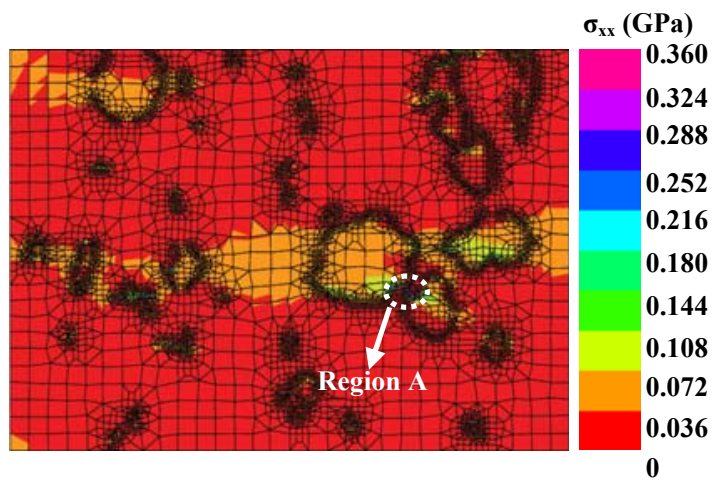

(d)

FIG. 6. 


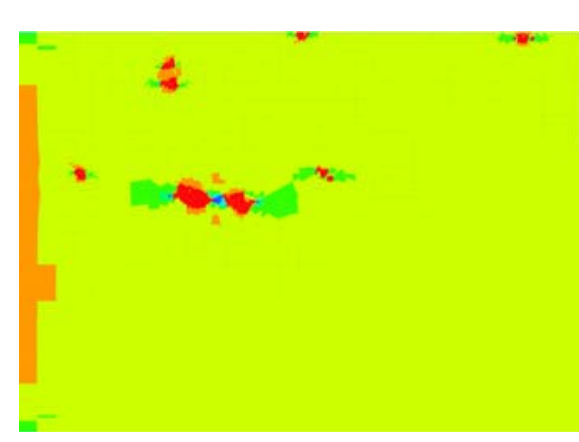

(a)

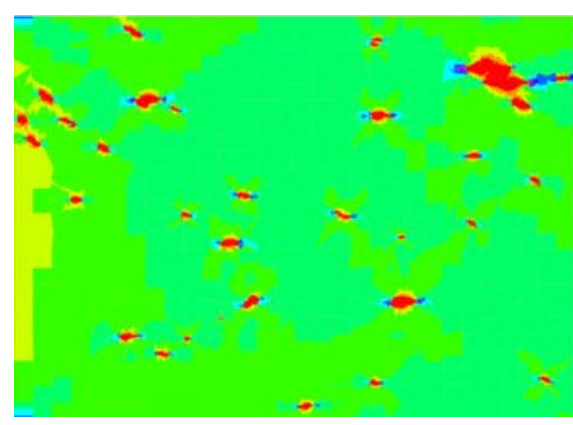

(c)
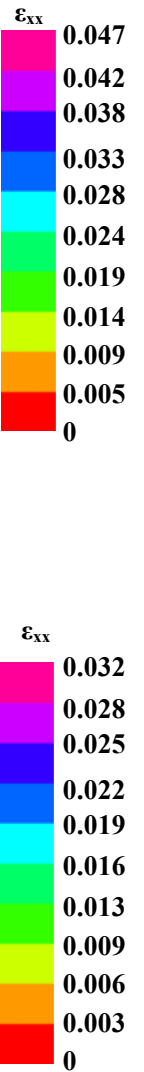

FIG. 7.

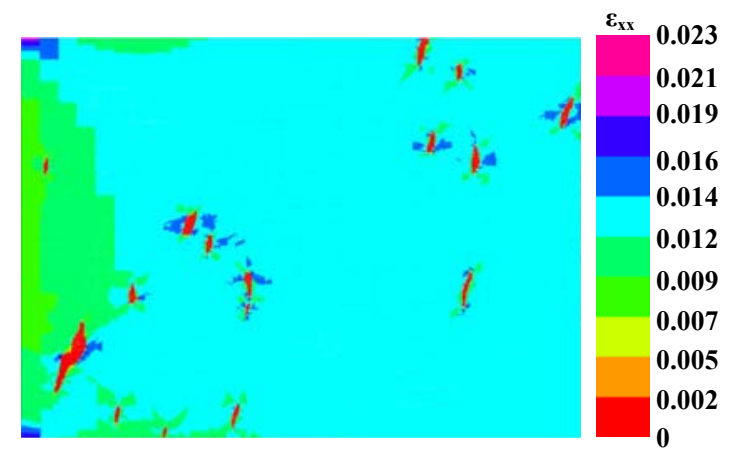

(b)

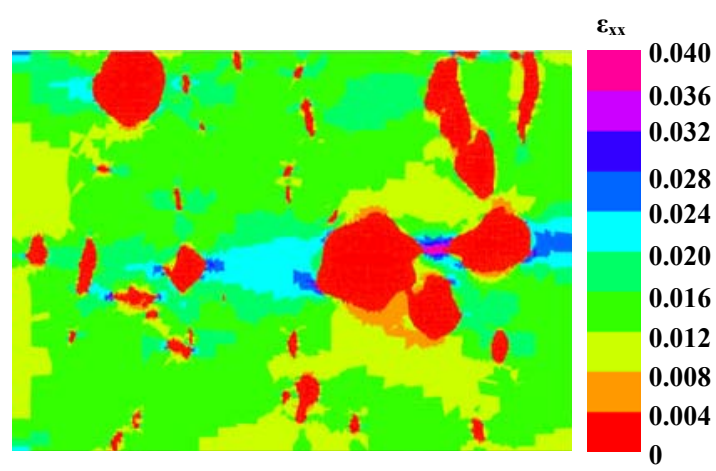

(d)

Table 1 Material properties of constituents in PP/clay nanocomposites

\begin{tabular}{|c|c|c|c|}
\hline & PP matrix & Clay particles & References \\
\hline $\begin{array}{l}\text { Young's modulus } \\
\text { (GPa) }\end{array}$ & $1.66^{\mathrm{a}}$ & $68.1^{\mathrm{b}}$ & $\begin{array}{l}\text { a Our experimental data; } \\
{ }^{\mathrm{b}} \text { Calculated on average from equation } \\
\text { (10) based on measured } \mathrm{d}_{001} \text { from }[23,24]\end{array}$ \\
\hline Poisson's Ratio & $0.35^{\mathrm{c}}$ & $0.26^{\mathrm{d}}$ & ${ }^{\mathrm{c}}[22]$ and ${ }^{\mathrm{d}}[21]$ \\
\hline Density $\left(\mathrm{g} / \mathrm{cm}^{3}\right)$ & 0.9 & 1.8 & Material data sheet \\
\hline
\end{tabular}

